\title{
Experimental and Theoretical Study of Sandwich Panels with Steel Facesheets and GFRP Core
}

\author{
Hai Fang, ${ }^{1}$ Huiyuan Shi, ${ }^{2}$ Yue Wang, ${ }^{1}$ Yujun Qi, ${ }^{1}$ and Weiqing Liu ${ }^{3}$ \\ ${ }^{1}$ College of Civil Engineering, Nanjing Tech University, Nanjing, China \\ ${ }^{2}$ School of Civil Engineering, Southeast University, Nanjing, China \\ ${ }^{3}$ Advanced Engineering Composites Research Center, Nanjing Tech University, Nanjing, China \\ Correspondence should be addressed to Weiqing Liu; wqliu@njtech.edu.cn
}

Received 2 May 2016; Accepted 25 July 2016

Academic Editor: Gianfranco Palumbo

Copyright (C) 2016 Hai Fang et al. This is an open access article distributed under the Creative Commons Attribution License, which permits unrestricted use, distribution, and reproduction in any medium, provided the original work is properly cited.

\begin{abstract}
This study presented a new form of composite sandwich panels, with steel plates as facesheets and bonded glass fiber-reinforced polymer (GFRP) pultruded hollow square tubes as core. In this novel panel, GFRP and steel were optimally combined to obtain high bending stiffness, strength, and good ductility. Four-point bending test was implemented to analyze the distribution of the stress, strain, mid-span deflection, and the ultimate failure mode. A section transformation method was used to evaluate the stress and the mid-span deflection of the sandwich panels. The theoretical values, experimental results, and FEM simulation values are compared and appeared to be in good agreement. The influence of thickness of steel facesheet on mid-span deflection and stress was simulated. The results showed that the mid-span deflection and stress decreased and the decent speed was getting smaller as the thickness of steel facesheet increases. A most effective thickness of steel facesheet was advised.
\end{abstract}

\section{Introduction}

In recent years, sandwich structures have been widely applied. A sandwich panel is a typical structural form with good structural performance and excellent material advantages, such as higher strength, better performance under shock absorption, and also a lower density compared to traditional monolayer materials [1-5]. Worldwide, study of metal sandwich panel structures has been ongoing since the 1950s and the related studies can be found in the publications of Allen [6]. Via experimentation, Davies [7] proposed the corresponding deflection calculation formulas on metalfaced sandwich panels, and Frostig and Baruch [8] studied the mechanical behavior of sandwich beams when the upper and lower facesheets were identical or different. Finnish scholar Frank et al. [9] evaluated the fatigue strength of laser-stakewelded, web-core, steel sandwich panels. A 3D-panel bending response was analyzed using the finite element method. The simulated values were compared with the experimental values and showed good agreement. Cambridge University [10] developed a type of sandwich beam comprising a Y-frame and corrugated cores that were manufactured by assembling and brazing prefolded AISI type 304 stainless steel sheets together and conducted three-point bending experiments to study its extreme loading capacity and failure mode; infinite element software was also used to simulate the number of core materials, the thickness of the core material, and the angle of the corrugation, and to propose an effective design method. Swedish scholars Kolsters and Zenkert [11] performed a compression test on the laser-welded, steel sandwich panels and determined the lateral pressure failure mode, the lateral pressure ultimate bearing capacity, and the corresponding strain curve for this type of sandwich panel. Based on panels' buckling theory, those authors also predicted the ultimate bearing capacity under the lateral pressure state for sandwich panels, and their calculated values were shown to be in good agreement with the experimental results. Swiss Keller [12] and his team developed a new type of hybrid bridge girder and conducted a series of studies that included static tests, fatigue tests, and theoretical calculations. They also used lightweight wood as the core material and GFRP as facesheet to make sandwich bridge decks. Huo et al. [13] found that the facesheet thickness affected the displacement ductility of GFFW decks. Seo et al. [14] presented the concept of material hybridization 
increasing elastic modulus of GFRP bars by using steel. Özes and Neşer [15] evaluated the adhesive bonding performance and the results reveal that the surface roughness of steel has a significant effect on the bonding performance of steel to FRP combinations. Metal sheets are used at the outer surfaces to maximize rigidity while inner lightweight cores are adhesively bonded with them to keep the whole structure together; this is inconsistent with the concept developed by Mamalis et al. [16]. The ASTM [17] formulated the buckling experiment methods and design specifications for multilayer sandwich panels.

Currently, there are still plenty of shortcomings to use the steel plate and sandwich steel plates used in bridge girders and ships, such as too many welding joints needed, easy corrosion, and difficultly maintained. It is rarely suitable to applications in complex stress states. Fiber reinforced polymer composite materials are gaining popularity as the materials of choice to replace deteriorated concrete bridge decks; two different FRP bridge decks were modeled for their dynamic responses by Prachasaree et al. [18]. In this paper, a novel composite sandwich panel is presented, consisting of steel slab as the top and bottom facesheet and middle hollow GFRP square tubes as core. The GFRP tubes are molded together with the steel facesheet during the manufacturing process. This type of composite sandwich panel has several advantages over traditional slabs: (1) Welding work can be avoided in process of manufacture and the amount of welding seam is reduced, (2) the panel has better antifire and antiageing performance as the GFRP tubes are protected by the steel facesheet, (3) the steel slab located on the surface is easy to maintain, and (4) the hollow GFRP square tube core can reduce the work required to reserve a variety of pipes and lines. It is mainly proposed for applications in ships, bridges, and buildings as its light weight, high strength, high stiffness, and good wear resistance. Use this kind of sandwich panels as bridge decks can avoid the disadvantages of low stiffness and easily split which the integral composite bridge decks have. Besides, applying this kind of sandwich panel in steel box girders can obtain smaller negative moment region due to its relatively high rigidity. In order to explore the flexural behavior of this steel-GFRP composite sandwich panel, a series of experimental studies was conducted under four-point bending. The ultimate bending capacity and mid-span deflection were calculated by the transformed section method. An FEM analytical model was developed to predict the ultimate bending capacity as well as the mid-span deflection of the panels.

\section{Experimental Program}

2.1. Specimen Preparation. The specimens created in this study were composed of steel facesheet, glass fiber reinforced plastic (GFRP) composite core, which was pultruded as hollow square tubs. Use the structural adhesive to bond the GFRP tubes together and the core was sharped. Apply structural adhesive on the surface of steel slab, paste the tube core onto it, place another piece of slab onto the tube core, and then apply pressure. The shaped specimen is shown in Figure 1.

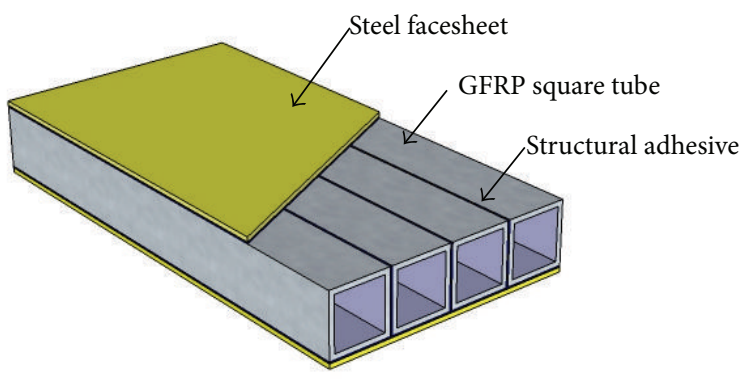

FIGURE 1: Schematic of the sandwich panel.

TABLE 1: Description of specimens of steel-GFRP sandwich panels.

\begin{tabular}{|c|c|}
\hline Specimen & Specimen \\
\hline$S(0)-G F R P$ & GFRP hollow tube (without facesheet) \\
\hline S(4)-GFRP & $\begin{array}{c}\text { Steel facesheet (thickness: } 4 \mathrm{~mm} \text { ) + GFRP hollow } \\
\text { tube core }\end{array}$ \\
\hline S(6)-GFRP & $\begin{array}{c}\text { Steel facesheet (thickness: } 6 \mathrm{~mm} \text { ) + GFRP hollow } \\
\text { tube core }\end{array}$ \\
\hline$S(8)-G F R P$ & $\begin{array}{c}\text { Steel facesheet (thickness: } 8 \mathrm{~mm} \text { ) + GFRP hollow } \\
\text { tube core }\end{array}$ \\
\hline S(10)-GFRP & $\begin{array}{c}\text { Steel facesheet (thickness: } 10 \mathrm{~mm} \text { ) + GFRP hollow } \\
\text { tube core }\end{array}$ \\
\hline F(6)-GFRP & $\begin{array}{c}\text { GFRP facesheet (thickness: } 6 \mathrm{~mm} \text { ) + GFRP } \\
\text { hollow tube core }\end{array}$ \\
\hline
\end{tabular}

Note: in the specimens' names, "S" represents a steel facesheet, and the figure following it represents the thickness of steel facesheet; "F" represents GFRP facesheet, and "GFRP" represents the composite tube core.

TABle 2: Size of specimens (unit: $\mathrm{mm}$ ).

\begin{tabular}{lcccc}
\hline Specimens & Length & Width & $\begin{array}{c}\text { Thickness of } \\
\text { facesheet }\end{array}$ & $\begin{array}{c}\text { Height of } \\
\text { core }\end{array}$ \\
\hline S(0)-GFRP & 1800 & 300 & - & 75 \\
S(4)-GFRP & 1800 & 300 & 4 & 75 \\
S(6)-GFRP & 1800 & 300 & 6 & 75 \\
S(8)-GFRP & 1800 & 300 & 8 & 75 \\
S(10)-GFRP & 1800 & 300 & 10 & 75 \\
F(6)-GFRP & 1800 & 300 & 6 & 75 \\
\hline
\end{tabular}

One GFRP hollow specimen, four sandwich specimens with steel facesheet and GFRP core, and one specimen with GFRP facesheet and GFRP core were prepared, as shown in Table 1. The heights of the core materials were all $75 \mathrm{~mm}$, and the widths were all $300 \mathrm{~mm}$. The thicknesses of steel facesheets were $4,6,8$, and $10 \mathrm{~mm}$, and that of GFPR facesheet was $6 \mathrm{~mm}$, with identical width of $300 \mathrm{~mm}$. The sizes of the specimens are shown in Table 2.

2.2. Material Properties. The tensile strength and Young's modulus of GFRP were determined as per ASTM D3039/D 3039M-14 [19]. The strength and modulus and Poisson's ratio of the steel slab, GFRP slab, and GFRP core of this innovative composite sandwich panel are given in Table 3, respectively. It was concluded, therefore, that the sequence of steel and GFRP 
TABLE 3: The material properties of GFRP and steel.

\begin{tabular}{lccccccccc}
\hline Beam component & $E_{1}(\mathrm{~Pa})$ & $E_{2}(\mathrm{~Pa})$ & $E_{3}(\mathrm{~Pa})$ & $v_{12}$ & $v_{13}$ & $v_{23}$ & $G_{12}(\mathrm{~Pa})$ & $G_{13}(\mathrm{~Pa})$ & $G_{23}(\mathrm{~Pa})$ \\
\hline GFRP facesheet & $1.36 E 10$ & $2.50 E 9$ & $2.50 E 9$ & 0.15 & 0.15 & 0.15 & - & - \\
GFRP core & $2.42 E 10$ & $9.37 E 9$ & $9.37 E 9$ & 0.18 & 0.18 & 0.18 & $3.63 E 8$ & $2.75 E 8$ \\
Steel facesheet & $1.95 E 11$ & $1.95 E 11$ & $1.95 E 11$ & 0.31 & 0.31 & 0.31 & - & - \\
\hline
\end{tabular}

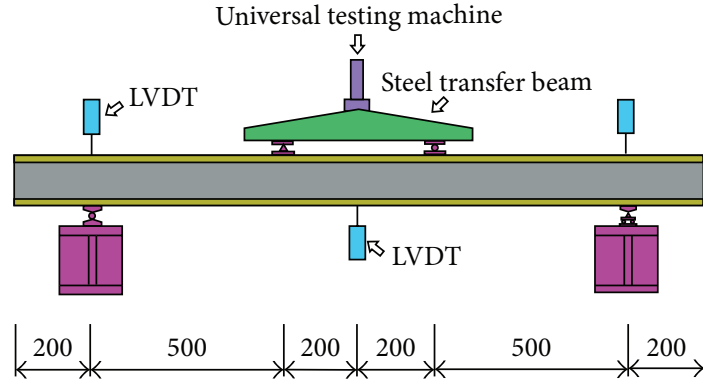

FIGURE 2: Schematic illustration of the test.

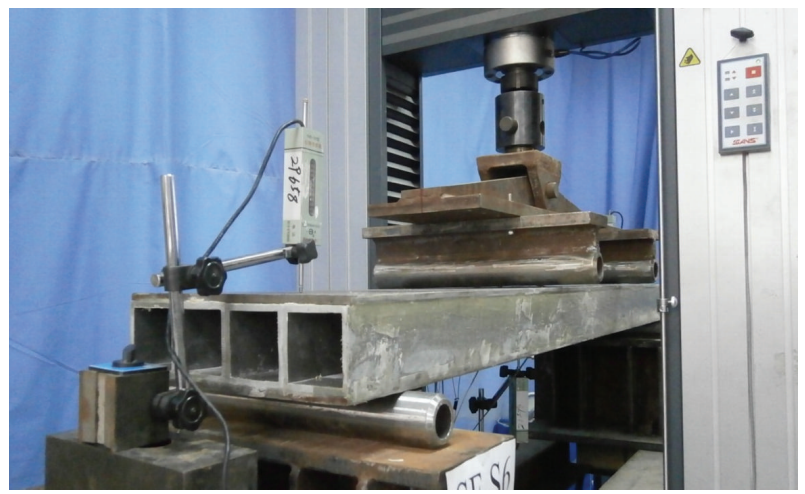

FIgURE 3: Flexural test setup.

might give optimized structural stiffness and load carrying capacity of the resulting sandwich configuration.

2.3. Experimental Setup and Loading Procedure. A 4-point static bending test was performed on the innovative sandwich panels with different thicknesses of steel or GFRP facesheet in accordance with the ASTM C393-00 standard [17]. The experiments mainly evaluated the flexural stiffness and ultimate flexural strength of sandwich panels with different configurations. The experiments in this study used a universal testing machine to apply static loads based on the experimental method to determine the bending performance of the sandwich structure. The schematic illustration and loading setup used in the experiments are shown in Figures 2 and 3, respectively.

Specimens in the bending tests were named according to the two parts, for example, S(4)-GFRP and F(6)-GFRP, where the first part with $S$ (or F) represents that the material of facesheet was steel (or GFRP), the number represents the thickness of the layer in $\mathrm{mm}$, and the second part GFRP represents the material of the core.
The loading was applied $250 \mathrm{~mm}$ from the mid-span through a spreader panel using a $200 \mathrm{kN}$ universal testing machine with a loading rate of $1 \mathrm{kN} / \mathrm{min}$. Before each test, the loading pins were set to almost touch the upper surface of the composite sandwich specimen. The applied load, displacement, and strains were recorded using a data logger, linear variable differential transducer (LVDT, made by Mitutoyo Corporation, with a precision of 25 micrometers), and strain gauges (MM CEA-06-1250UW-350). Failure mechanisms were also monitored and recorded.

\section{Experimental Results and Discussions}

3.1. Failure Behavior. Experimental investigation showed that the sandwich panels with different facesheets exhibited different failure behaviors. These different failure modes are shown in Figures 4-9. These test results showed that, due to the support of the steel or GFRP facesheet, the panels showed better stiffness and bearing abilities. No collapse of the facesheet occurred. Meanwhile, local failure of the GFRP tube core was avoided in the loading point region.

Specimen SF had a low stiffness as it did not have an upper or lower facesheet. As the load increases, the deflection quickly increased as well. When the load was increased to $94 \mathrm{kN}$, the GFRP tube suddenly produced a ripping sound, and cracks were noted on the web beneath the loading points. With continued loading, cracks appeared on the web between the loading points, as shown in Figure 4(a), and a significant cracking sound from GFRP was heard, and cracks also appeared on the facesheet between the loading points, as shown in Figure 4(b); these cracks spread to both sides of the specimen, as shown in Figure 4(c). Keeping loading, the load remained stable while deflection increased rapidly.

The upper and lower facesheets of specimen S(4)-GFRP were $4 \mathrm{~mm}$ steel plates. As the load increased, the deflection increased gradually without other significant phenomena. When the load had increased to $104 \mathrm{kN}$, a "snapping" sound was heard. After the load was increased to $128 \mathrm{kN}$, the steel plate of the upper facesheet between the loading points peeled off and delaminated from the composite square tube, as shown in Figure 5(a). Keeping loading, a continuous tearing sound was heard, and tearing failure appeared where the web between the loading points and the upper and lower facesheets intersected, as shown in Figure 5(b).

The thickness of the upper and lower steel facesheets of specimen S(6)-GFRP was $6 \mathrm{~mm}$. No significant phenomenon was noted during the initial loading stage. When the load increased to $132 \mathrm{kN}$, "snapping" sounds were heard. As the load increased, sounds could be heard continuously. When a sudden loud sound was heard, the web peeled off and delaminated from the lower facesheet, as shown in Figure 6(a). The 


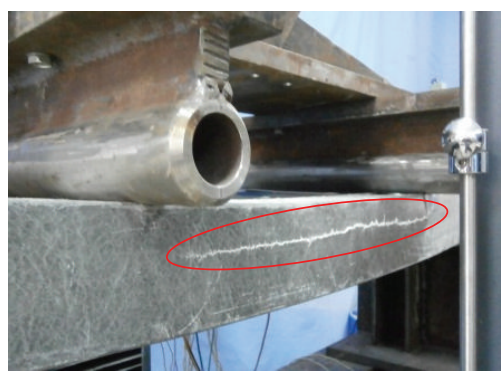

(a)

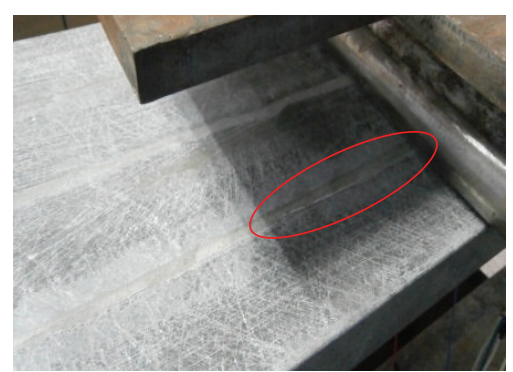

(b)

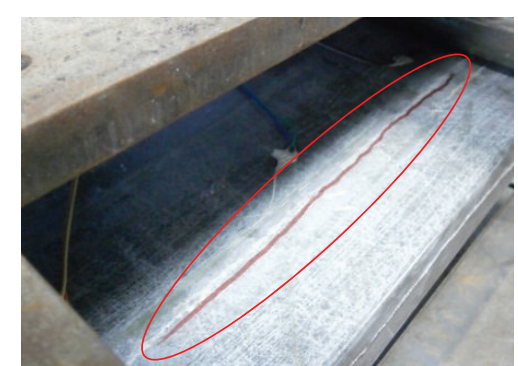

(c)

FIGURE 4: Failure of specimen S(0)-GFRP: (a) horizontal cracks appeared on the web, (b) cracks appeared on the facesheet, and (c) cracks spreading.

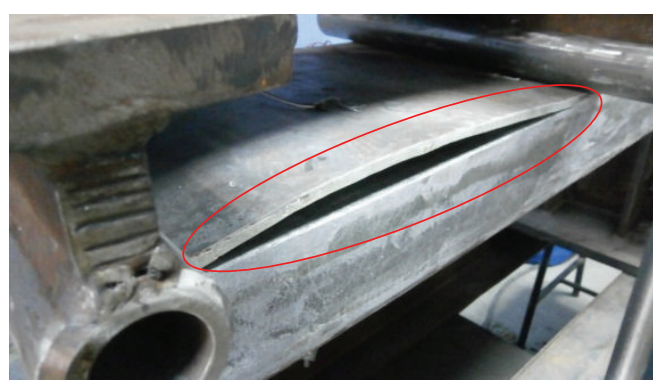

(a)

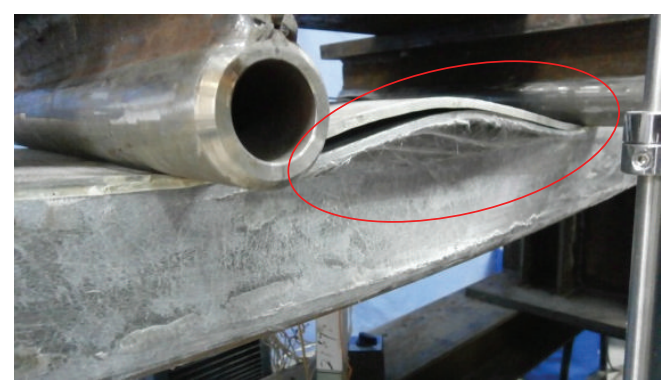

(b)

FIGURE 5: Failure of specimen S(4)-GFRP: (a) peeling off and delaminating and (b) tearing failure of the web where it intersected the facesheet.

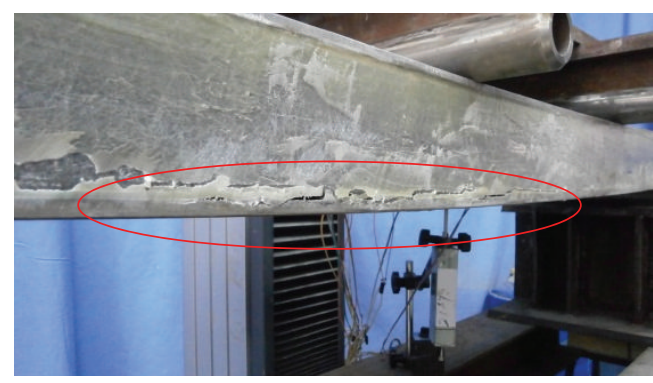

(a)

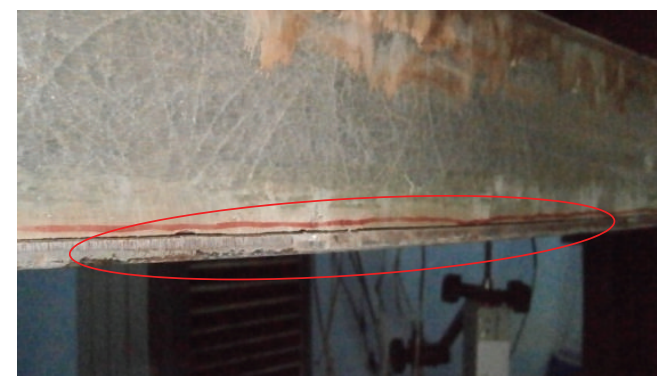

(b)

FIGURE 6: Failure of specimen S(6)-GFRP: (a) web peeling off from the lower facesheet and (b) web on the other side peeling off from the lower facesheet.

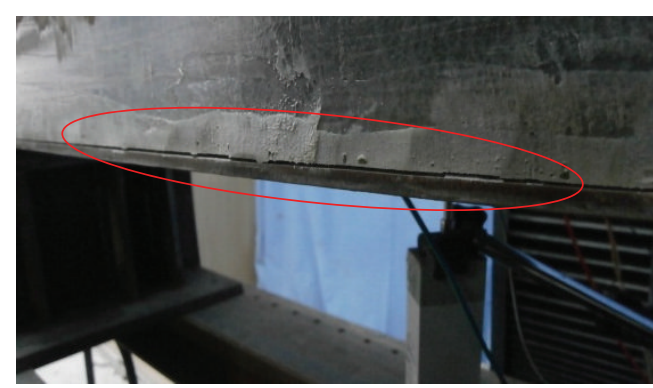

(a)

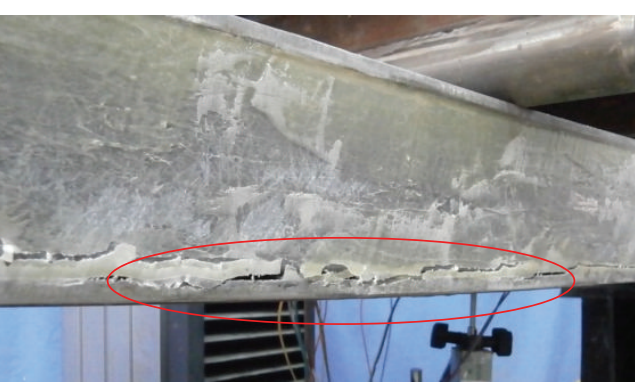

(b)

FIGURE 7: Failure of specimen S(8)-GFRP: (a) web peeling off from the lower facesheet and (b) web on the other side delaminating from the lower facesheet. 


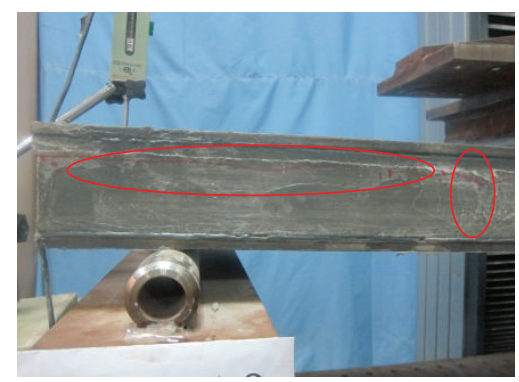

(a)

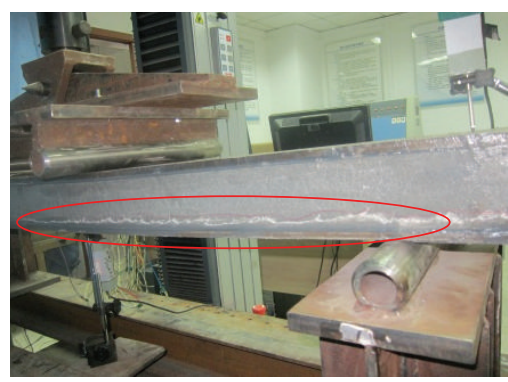

(b)

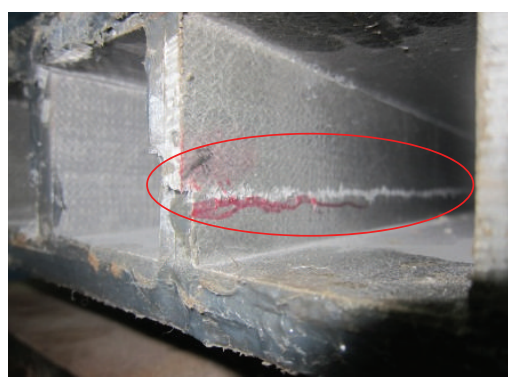

(c)

FIGURE 8: Failure of specimen S(10)-GFRP: (a) spreading of cracks, (b) cracks appearing where the web and the lower facesheet intersected, and (c) breaking of specimen rib.

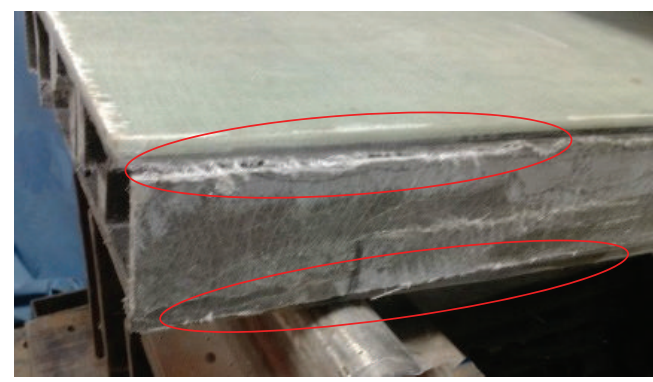

(a)

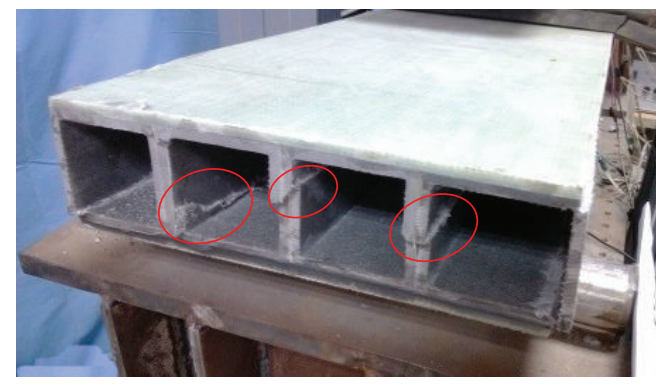

(b)

FIGURE 9: Failure of specimen F(6)-GFRP: (a) cracks spreading horizontally and (b) rib fracture.

web on the other side also peeled off from the lower facesheet. Keeping loading, this phenomenon became more significant, as shown in Figure 6(b), and the specimen failed.

The thickness of the upper and lower steel facesheets of specimen S(8)-GFRP was $8 \mathrm{~mm}$. Because the steel plate was thicker compared to the previous tests, this specimen had a high rigidity. Small sounds could be heard during the loading process. However, there was no significant or abnormal phenomenon that was visible. When the load increased to $148 \mathrm{kN}$, the specimen produced a small snapping sound. With continuous loading, small sounds could be heard, but no visible cracks appeared. When the load was $152 \mathrm{kN}$, a loud tearing sound was heard, and the load decreased to $85 \mathrm{kN}$ rapidly at the same time. The specimen had peeled off from the lower facesheet, as shown in Figure 7(a). Keeping loading, the web on the other side of the specimen also delaminated from the lower facesheet, as shown in Figure 7(b).

The thickness of the upper and lower steel facesheets of specimen S(10)-GFRP was $10 \mathrm{~mm}$ As the load increased, the displacement grew slowly. When the load was $189 \mathrm{kN}$, the specimen produced a small sound. With increasing load, continuous "snapping" sounds could be heard. When the load was increased to $204 \mathrm{kN}$, a significant tearing sound was heard. At this time, cracks appeared where the web and the upper facesheet intersected, and as the load increased, the cracks expanded along the fiber direction, as shown in Figure 8(a). At this time, horizontal cracks also appeared where the web on the other side and the facesheets intersected, as shown in Figure 8(b). When the load was increased to $212 \mathrm{kN}$, a loud sound was heard, and the load decreased to $76 \mathrm{kN}$; at this time, the middle rib of the specimen broke, as shown in Figure 8(c), which indicated that the specimen had failed.

The upper and lower layers of specimen F(6)-GFRP were $6 \mathrm{~mm}$ GFRP plates. As the load increased, small sounds could be heard coming from the specimen. No abnormal phenomenon was found using naked-eye observation. When the load was increased to $180 \mathrm{kN}$, cracking sounds were heard but no abnormal phenomenon was visible. When the load was increased to $187 \mathrm{kN}$, another significant cracking sound could be heard; cracks were then found where the web and the upper facesheet intersected, as shown in Figure 9(a). Keeping loading, cracks also appeared at interface of the web and the lower facesheet and spread along the horizontal direction. When the load was increased to $191 \mathrm{kN}$, a big sound was heard, and the middle rib of the specimen was found to have broken, as shown in Figure 9(b); loading was stopped at this time.

\subsection{Effect of Steel Thickness on Panel Flexural Properties.} Analyzing the load-deflection curve in Figure 10, it is shown that the specimens exhibited good agreement before failure. As the thickness of the facesheets increased, the midspan deflection decreased gradually, and the declining scope became more evident as the facesheet thickness increased. When the facesheet thickness is increased from 4 to $10 \mathrm{~mm}$ in $2 \mathrm{~mm}$ steps, the mid-span displacements are reduced 


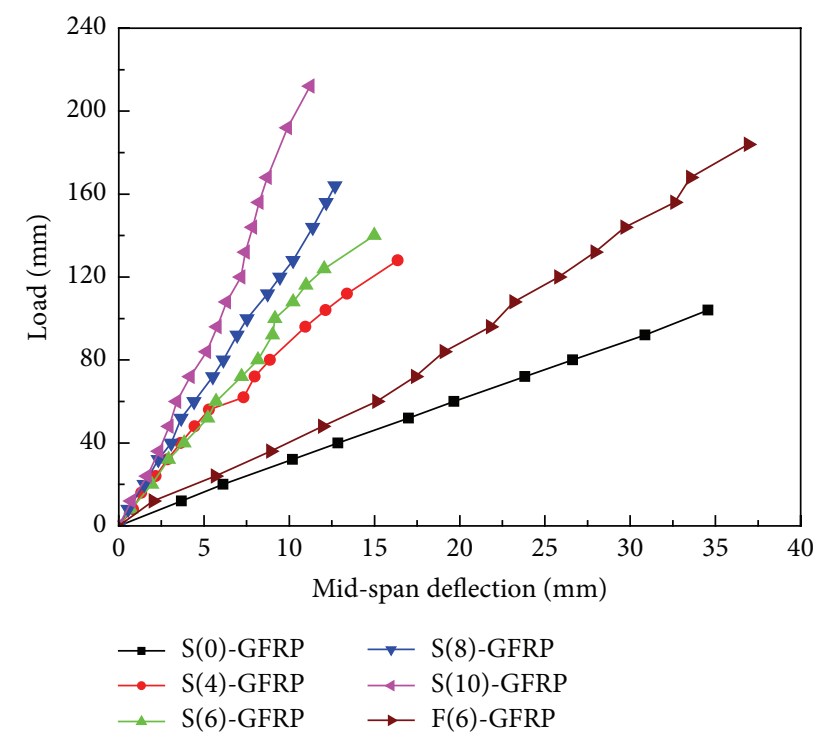

Figure 10: Load-deflection curves.

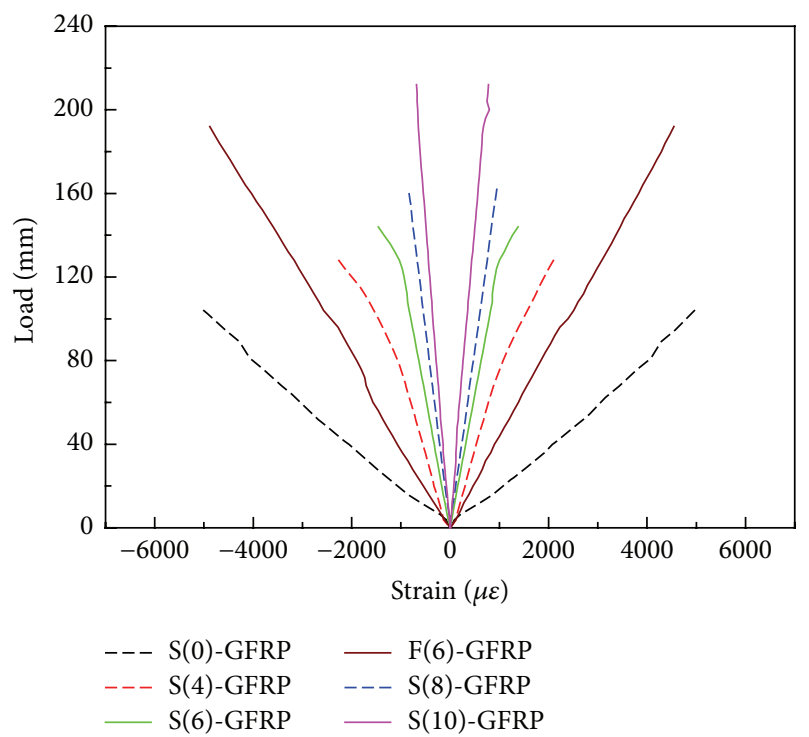

FIgURE 11: Mid-span load-strain curves.

by $8.4 \%, 15.4 \%$, and $11.5 \%$, respectively. The ultimate load of the specimens also increased when the thickness of facesheets increased. The specimen F(6)-GFRP had greater stiffness than $\mathrm{S}(0)$-GFRP, but its stiffness was much smaller compared with the specimen with steel facesheet. Adhesive failure occurred to the facesheet and the sandwich core for specimens S(4)-GFRP, S(6)-GFRP, and S(8)-GFRP. This type of failure happened suddenly, which should be avoided as much as possible in real designs.

As shown in Figure 11, the sandwich panel without a facesheet exhibited poor ductility and the curve was almost linear. With the thickness of the steel facesheets increasing, the mid-span strain decreased. It showed that the upper and lower steel facesheets' strains were evenly distributed when

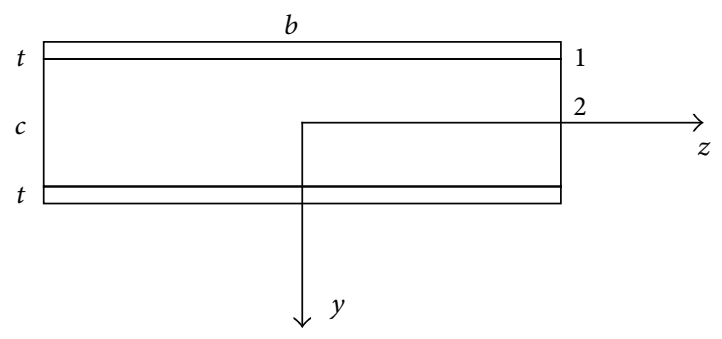

Figure 12: Section of the sandwich panel.

loads were moderate, and the stiffness of the system was fully used. Overall, the strains at the upper and lower symmetrical positions of the neutral axis were similar. Besides, the elastic behavior of the strain distribution was observed at the early stage of loading in all specimens.

\section{Theoretical Analysis}

This study used sandwich beam theory and transformed section theory combined with the material mechanics method to deduce the formula for the stress and mid-span deflection of the sandwich panel. Steel and GFRP materials are both considered ideal elastomers. The transition between different materials is continuous, and the slippage between interfaces is neglected.

4.1. Transformed Section Theory. The sandwich panels that consisted of steel and composite materials can be transformed into the section of the same material. For the steel facesheetGFRP core section unit, it is assumed that the area is $A_{f}$, the elastic modulus is $E_{f}$, and there is a strain $\varepsilon_{f}$ under the action of stress $\sigma_{f}$. Then, based on the equivalent condition that the strain is the same, and the total force is constant, the steel facesheet unit can be used to describe the elastic modulus $E_{f}$, the stress $\sigma_{f}$, and the core's equivalent converted section area $A_{c f}$. The diagram of the panel section is shown in Figure 12, where $t$ and $c$ describe the thicknesses of the steel plate and the GFRP core, respectively; and the number 1 indicates the steel face, and the number 2 indicates the GFRP core.

Taking the steel facesheet as an example, as the strain is the same, it is assumed that the coefficient $\alpha_{E_{f}}$ is the ratio of the core's elastic modulus $E_{c}$ to the steel plate's elastic modulus $E_{f}$; thus

$$
\frac{\sigma_{f}}{\sigma_{c}}=\frac{E_{f}}{E_{c}}=\frac{1}{\alpha_{E_{f}}} .
$$

Based on the condition that the total force is constant, it can be derived that

$$
A_{c f}=\frac{A_{f}}{\alpha_{E_{f}}} .
$$

During the section's conversion process, it is required that the section centroid remains unchanged before and after conversion; therefore, the thickness of the steel plate must 


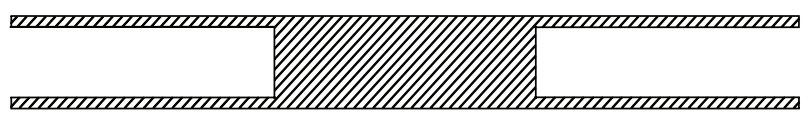

Figure 13: Conversion section.

remain unchanged, and thus, the area conversion is equal to the width conversion (i.e., $b$ is converted to $b_{c f}$ ):

$$
b_{c f}=\frac{b}{\alpha_{E_{f}}} .
$$

The converted width $b_{c f}$ can now be derived. Then, based on the converted section (Figure 12), the inertia moment $I_{c f}$ can be calculated for the converted GFRP section, as shown in Figure 13.

4.2. Stress Analysis. On the basis of the distribution of the strain as shown in Figure 11, the plane section assumption is applicable for the early stage of loading. The full section remains plane until the specimen reaches the limit condition.

Combining each layer as a whole, the strain can be expressed as

$$
\varepsilon_{x}=\frac{y}{\rho},
$$

where $\rho$ is the radius of deflection curve and $y$ is the distance from any point to the neutral. The stress of the steel facesheet and GFRP core can be expressed as

$$
\begin{aligned}
\sigma_{f} & =\frac{y}{\rho} E_{f}, \\
\sigma_{c} & =\frac{y}{\rho} E_{c},
\end{aligned}
$$

where $E_{f}$ and $E_{c}$ are the elastic modulus of the facesheet and core, respectively. The bending moment within the beam's cross section is derived to be

$$
M=2 \int_{A_{f}} y \sigma_{f} d A_{f}+\int_{A_{f}} y \sigma_{c} d A_{c} .
$$

Substitute (4) and (5) into (6) and simplify

$$
M=\frac{1}{\rho}\left(2 E_{f} I_{f}+E_{c} I_{c}\right),
$$

where the integral areas $A_{f}=b t$ and $A_{c}=b c$ and $t$ and $c$ are the thicknesses of the steel plate and the GFRP core, respectively; $b$ is the beam width; $I_{f}$ and $I_{c}$ are the moment of inertia of the facesheet and core, respectively.

Substitute (7) into (5), and then the stresses for the steel facesheet and the core material should, respectively, be

$$
\begin{gathered}
\sigma_{c}=\frac{M y E_{c}}{2 E_{f} I_{f}+E_{c} I_{c}}=\frac{M y}{2\left(E_{f} / E_{c}\right) I_{f}+I_{c}}, \\
\sigma_{f}=\frac{M y E_{f}}{2 E_{f} I_{f}+E_{c} I_{c}}=\frac{M y}{2 I_{f}+\left(E_{c} / E_{f}\right) I_{c}} .
\end{gathered}
$$

Simplify the formula, and then

$$
\begin{aligned}
\sigma_{f} & =\frac{M y}{I_{c f}}, \\
\sigma_{c} & =\frac{M y \alpha_{E_{f}}}{I_{c f}},
\end{aligned}
$$

where $I_{c f}$ is the equivalent cross-sectional moment of inertia.

To solve the interlayer shearing force, the differential equation of the equilibrium of the beam unit is first solved:

$$
\begin{aligned}
& \frac{\partial \sigma_{x}}{\partial x}+\frac{\partial \tau_{y x}}{\partial y}+f_{x}=0 \\
& \frac{\partial \sigma_{y}}{\partial y}+\frac{\partial \tau_{y x}}{\partial x}+f_{y}=0 .
\end{aligned}
$$

If the shearing force between the facesheet and core is to be solved, $\sigma_{f}$ should be incorporated into the differential equation of equilibrium to derive the integral form:

$$
\begin{aligned}
& \int_{y}^{c / 2+t} \frac{\partial \sigma_{f}}{\partial x} d y+\int_{\tau_{x y}}^{0} \frac{\partial \tau_{x y}}{\partial y} d y=0, \\
& \tau_{x y}=\frac{P}{2 I_{c z f}} \cdot \frac{(c / 2+t)^{2}-y^{2}}{2} .
\end{aligned}
$$

The shearing force of the facesheet and core is solved as

$$
\begin{aligned}
& \tau_{f}=\frac{V S_{f}}{I_{c f} t_{\text {eqf }}}, \\
& \tau_{c}=\frac{V S_{c}}{I_{c f} t_{w}},
\end{aligned}
$$

where $S_{f}$ and $S_{c}$ are the static moments of the area of transformed section below the calculating point to the neutral axis.

The bending stress is calculated based on (10), and the bending interlayer shearing force is calculated based on (13). Using specimen S(8)-GFRP as an example, an external load of $60 \mathrm{kN}$ is used for analysis in this study because this theory is valid only under the linear elastic range, and plasticity is often displayed in the failure margin of the sandwich beam. Based on the calculations, the distribution of the bending stress and shearing force of the sandwich beam section is shown in Figure 14. Table 4 compares the predicted maximum tensile and compressive stress with experimental results which were relative with strain of different components under a load of $60 \mathrm{kN}$. The stresses at the edge of tensile and compressive region of the sandwich panels can be calculated while the maximum tensile and compressive stress can be derived from homologous strain value measured in the experiment. The result of calculations shows an approximate agreement with the experimental values. The relative error between experimental and analytical results for specimens with steel facesheet and GFRP core is not more than 7.83\%. The maximum relative error is $10.64 \%$, which occurred in specimen $S(0)$-GFRP. 


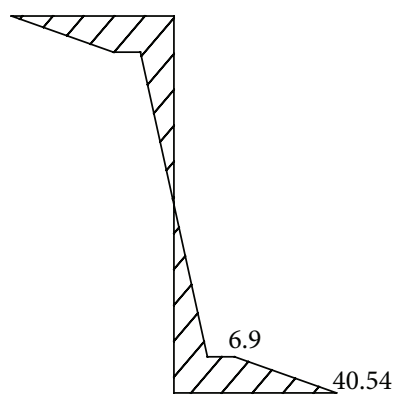

(a)

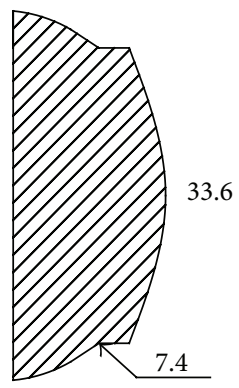

(b)

FIGURE 14: Sectional stress distribution at mid-span for specimen S(8)-GFRP: (a) normal stress and (b) shear stress (unit in MPa).

TABLE 4: Comparisons of maximum tensile and compressive stress between experimental and analytical results.

\begin{tabular}{lcccccccc}
\hline \multirow{2}{*}{ Specimen } & \multicolumn{2}{c}{ Experimental strain $(\mu \varepsilon)$} & \multicolumn{2}{c}{ Experimental stress (MPa) } & \multicolumn{2}{c}{ Predicted stress (MPa) } & \multicolumn{2}{c}{ Relative error (\%) } \\
& Tensile & Compressive & Tensile & Compressive & Tensile & Compressive & Tensile & Compressive \\
\hline S(0)-GFRP & 2998 & 2985 & 40.7728 & 40.596 & 36.85 & 36.85 & 10.64 & 10.16 \\
F(6)-GFRP & 1462 & 1448 & 35.3804 & 35.0416 & 32.26 & 32.26 & 9.67 & 8.62 \\
S(4)-GFRP & 345 & 351 & 67.275 & 68.445 & 63.73 & 63.73 & 5.56 & 7.39 \\
S(6)-GFRP & 261 & 275 & 50.895 & 53.625 & 49.73 & 49.73 & 2.34 & 7.83 \\
S(8)-GFRP & 211 & 217 & 41.145 & 42.315 & 40.54 & 40.54 & 1.49 & 4.37 \\
S(10)-GFRP & 167 & 171 & 32.565 & 33.345 & 32.11 & 32.11 & 1.41 & 3.84 \\
\hline
\end{tabular}

Note: the relative error is calculated based on the following formula: (results from the predicted stress - experimental stress)/experimental stress.

4.3. Deflection Analysis. When calculating the deflection of the panels, the effects of shear deformation should be considered because the shear modulus of the hollow core is small. Using first-order shear deformation theory, the midspan deflection of the panels is equal to

$$
\Delta=\frac{a p}{48 D}\left(3 l^{2}-4 a^{2}\right)+\frac{p l}{6 A G}
$$

where $a$ is the distance from the loading point to the abutment; $l$ is the distance between the beam abutments; $p$ is the load; and $D$ is the flexural rigidity, which can be derived by the equivalent inertia moment $I_{c f}$ using the transformed section method multiplied by the elastic modulus $E$ of the GFRP core; $A G$ is the shear stiffness.

Based on the shear displacement theory of a classical sandwich panel, and considering the real conditions of specimens in this study, as shown in Figure 15, the shear displacement can be calculated based on the geometric relation [20].

As seen in Figure 15, the straight line $A C B$ becomes the curve $A^{\prime} C B^{\prime}$ due to shear displacement, and the point $p$ generates the corresponding displacement $u$. The distance $B B^{\prime}$ can be calculated by $z=c / 2$; thus

$$
B B^{\prime}=\frac{Q}{G D}\left(\frac{E_{f} t d c}{4}+\frac{E_{c} c^{3}}{24}\right)
$$

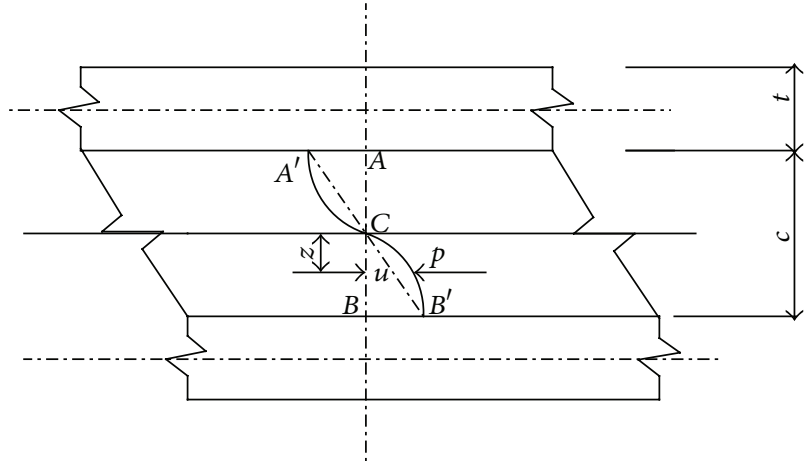

FIGURE 15: Shear displacement of sandwich panel.

It is assumed that the core is replaced by an antiplane core material whose shear modulus is $G^{\prime}$ but elastic modulus is $D$. The horizontal displacement of $B B^{\prime}$ should be expressed as

$$
B B^{\prime}=\frac{Q}{G^{\prime} D}\left(\frac{E_{f} t d c}{4}\right) .
$$

The equivalent shear modulus $G^{\prime}$ of the core can be derived as [6]

$$
G^{\prime}=\frac{G}{1+E_{c} / 6 E_{f} \cdot c^{2} / t(c+t)} .
$$


TABLE 5: Comparisons of flexural capacity between experimental and FEM results.

\begin{tabular}{|c|c|c|c|c|c|c|}
\hline \multirow{2}{*}{$\begin{array}{l}\text { Serial number of } \\
\text { specimen }\end{array}$} & \multicolumn{3}{|c|}{ Ultimate flexural capacity $(\mathrm{kN})$} & \multicolumn{3}{|c|}{ Ultimate displacement (mm) } \\
\hline & $\begin{array}{c}\text { Finite element } \\
\text { results }\end{array}$ & $\begin{array}{c}\text { Experimental } \\
\text { value }\end{array}$ & $\begin{array}{c}\text { Relative error } \\
(\%)\end{array}$ & $\begin{array}{c}\text { Finite element } \\
\text { results }\end{array}$ & $\begin{array}{l}\text { Experimental } \\
\text { value }\end{array}$ & $\begin{array}{c}\text { Relative error } \\
(\%)\end{array}$ \\
\hline$S(0)$-GFRP & 91 & 104 & -12.5 & 17.82 & 19.87 & -10.3 \\
\hline$F(6)-G F R P$ & 169 & 184 & -8.1 & 14.1 & 15.13 & -6.8 \\
\hline S(4)-GFRP & 114 & 128 & -10.9 & 6.53 & 7.13 & -8.5 \\
\hline$S(6)-G F R P$ & 129 & 140 & -7.8 & 5.4 & 5.72 & -5.6 \\
\hline S(8)-GFRP & 171 & 164 & 4.3 & 4.27 & 4.41 & -3.2 \\
\hline S(10)-GFRP & 197 & 212 & -7.1 & 3.02 & 3.5 & -13.7 \\
\hline
\end{tabular}

Note: the relative error is calculated based on the following formula: (results from the finite element method - experimental results)/experimental values.

The equivalent shear stiffness of the sandwich panel could be approximated as

$$
A G=\frac{b G^{\prime} d^{2}}{c}
$$

where $d$ is the sum of the thickness of the core and the thickness of a single facesheet; $c$ is the thickness of core; $t$ is the thickness of the facesheet; $b$ is the width of the sandwich beam; $A$ is the area of the shear section; and $G$ is the shear modulus. To verify the validity of the deflection calculation method, comparison between experimental and analytical results for specimens $\mathrm{S}(6)$-GFRP and S(8)-GFRP under load of $60 \mathrm{kN}$ is shown in Figures 17 and 18.

\section{FEM Simulation}

5.1. Finite Element Modeling and Validation. The finite element model was further developed to predict the mechanical performance of the sandwich by using ANSYS $^{\mathrm{TM}}$ commercial program. The models of sandwich panel with different facesheet thickness were modeled using 3D linear finite element analysis. Four-node SHELL 181 elements were used to simulate the skins and eight-node SOLID 185 elements were used to simulate the core. In total, 8100 SHELL 181 elements were used, as the upper and lower steel facesheet were divided into 4050 elements, respectively. At the same time, 16740 SOLID 185 elements were utilised for modeling the GFRP core. Each material had a lamina property with a longitudinal elastic modulus of direction $\left(E_{x}\right)$, a transverse elastic modulus $\left(E_{y}\right)$, an elastic modulus in the depth direction $\left(E_{z}\right)$, shear modulus of rigidity $\left(G_{x z}, G_{y z}, G_{x y}\right)$, and Poisson ratio $\left(v_{x y}, v_{y z}, v_{z x}\right)$. The applied load was imposed as four points bending in accordance with the experimental setup. The solution was obtained through a series of load increments. The simulated results were then compared with the experimental and theoretical values. Figure 16 shows the finite element model of the steel facesheet-GFRP core sandwich panel.

Based on Table 5, the FE and experimental results showed good agreement. Due to the deficiencies of the specimens in the experiment and other uncertain factors, the values of the mid-span deflection obtained experimentally were smaller than the theoretically calculated values, which were conservative; this is plausible for structure designs. Under the action of the load applied in the experiments, the materials were all in their elastic-deformation region, and the developing tendencies of the load-displacement curve for the three specimens were found to generally be in agreement. These results suggest that the FE model could be used as a design approach to evaluate the bending performance of sandwich panels.

Under the same load $(60 \mathrm{kN})$, using specimens $\mathrm{S}(6)$ GFRP and S(8)-GFRP as examples to verify the precision of the transformed section method, the elastic stage of each specimen was investigated. A comparison of the experimental, theoretical, and simulated values of the mid-span displacement is shown in Figures 17 and 18. The comparisons of numerical and analysis results to the experimental data show that the method is rather precise and is a useful auxiliary means for research work, design, and test.

5.2. Parametric Analysis. The finite element simulation of the steel facesheet composite core, sandwich panel structure's four-point bending stress exhibits good precision. Therefore, an ANSYS infinite element model is used to simulate more parameters of the bending performance of the structure to mitigate the lack of additional specimens, which is unsuitable for expanded analyses.

The validated modeling approach was then used to investigate the bending behavior of the sandwich beams with various thicknesses of steel facesheet. It is assumed that the total height of the steel-faced, composite, sandwich panel structure is $95 \mathrm{~mm}$; the facesheet thickness for modeling is set as $0,1.5,3,4.5,6,7.5,9,10.5$, and $12 \mathrm{~mm}$, and the load remains equal to $60 \mathrm{kN}$. The mid-span deflection and stress changed as the facesheet thickness increased, as shown in Figures 19 and 20. Both the mid-span deflection and stress decreased with the facesheet thickness increasing. The midspan deflection of specimen decreased by 5.5, 3.7, 3.1, 0.7, $1.3,0.4,0.6$, and $0.2 \mathrm{~mm}$ when the thickness of the facesheet increased by $1.5 \mathrm{~mm}$ from 0 to $12 \mathrm{~mm}$; at the same time, the mid-span stress of decreased by $28.8,17.9,16.9,6.6,6.5,4.1$, 5.8 , and $1.6 \mathrm{~mm}$. When the thickness of the facesheet changes from 0 to $4.5 \mathrm{~mm}$, the speed at which the sandwich beam's 


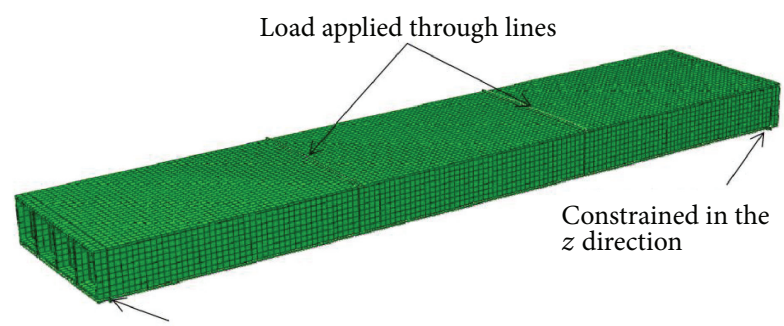

Constrained in the $x$ and $y$ directions

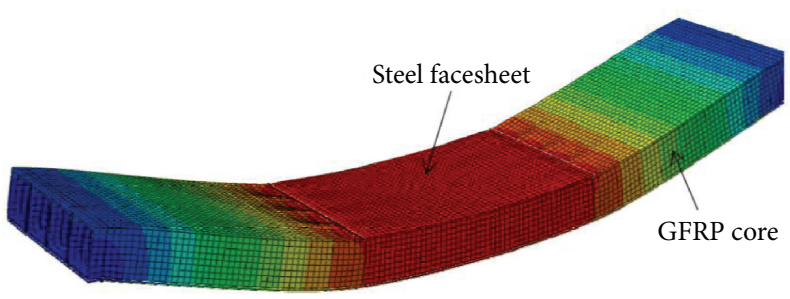

(b)

FIGURE 16: Finite element model for the sandwich panel specimen: (a) meshing and loading setup and (b) deformed shape.

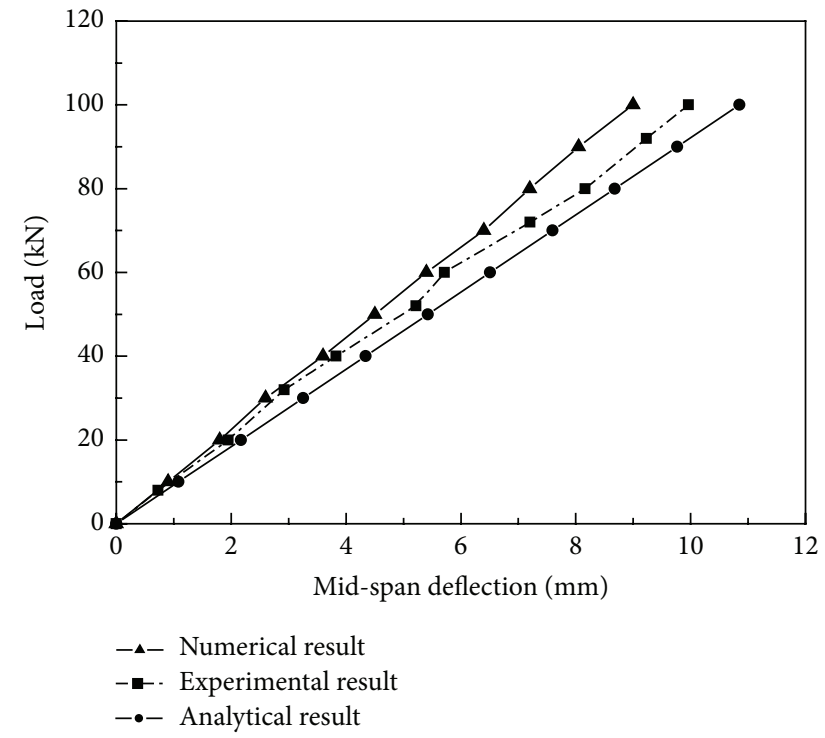

FIGURE 17: Contrast of the mid-span deflections of specimen S(6)GFRP.

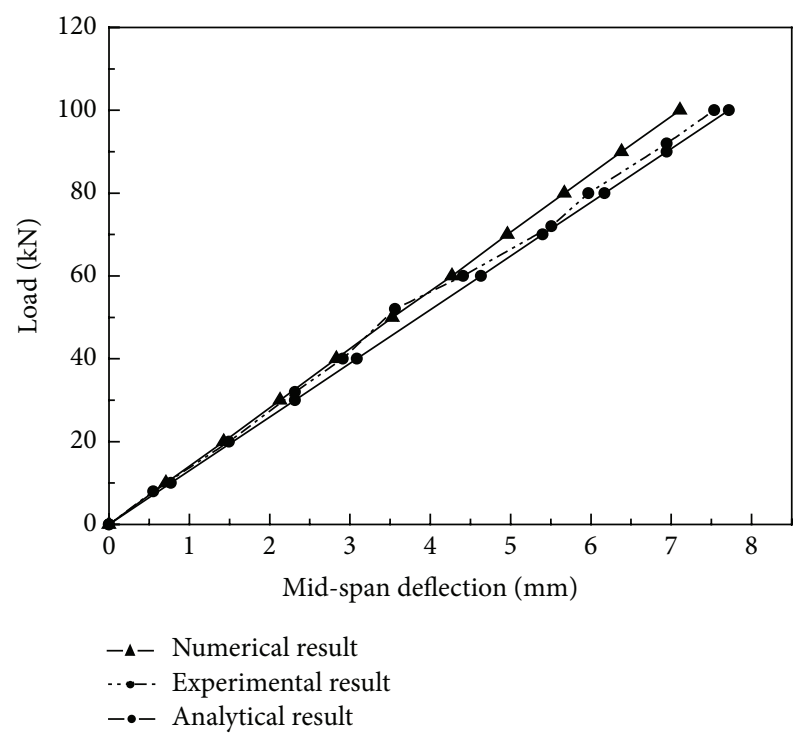

FIGURE 18: Contrast of the mid-span deflections of specimen S(8)GFRP.

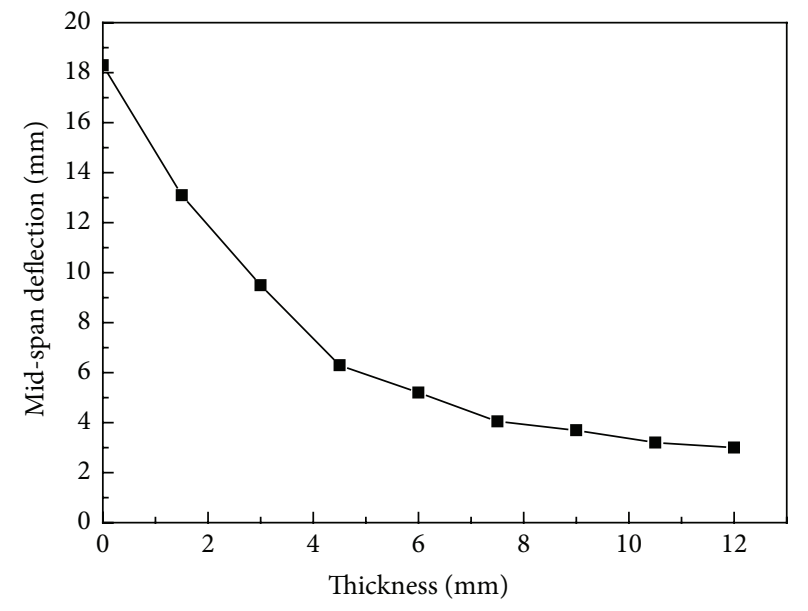

Figure 19: Effect of thickness of steel facesheet on mid-span deflection.

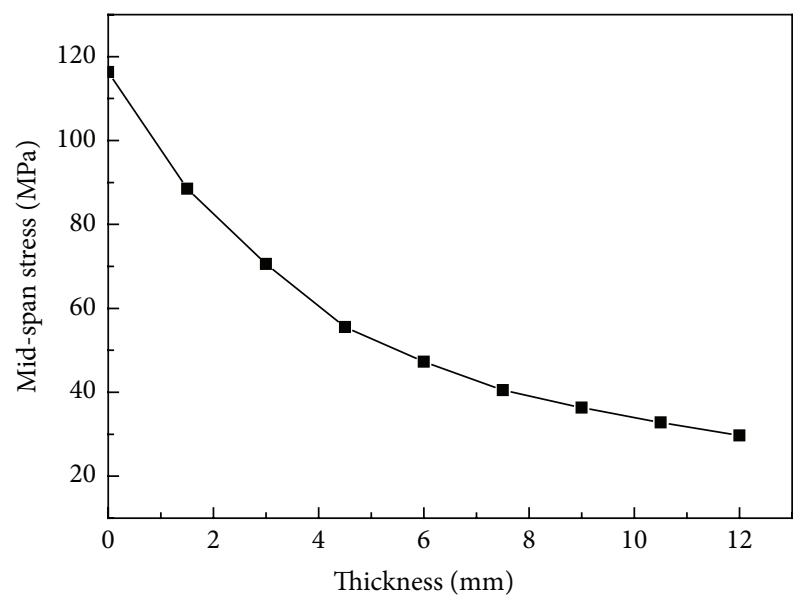

FIGURE 20: Effect of thickness of steel facesheet on mid-span stress.

mid-span deflection decreases is large; conversely, when the thickness of the facesheet is increased above $4.5 \mathrm{~mm}$, the rate of decrease is less significant. This is also true for the normal stress of the mid-span panel. Therefore, for a sandwich beam with a total height of $95 \mathrm{~mm}$, it is most effective to use a $4.5 \mathrm{~mm}$ thick facesheet. 


\section{Conclusions}

An innovative steel-GFRP sandwich panel was introduced in this study. Experiments were conducted to investigate the effects of the steel and GFRP facesheets on the overall structural performance in bending. FE modeling was used to parametrically analyze the material efficiency and to obtain an optimal solution for the thickness of steel facesheet. From this work, the following conclusions can be drawn:

(1) The adhesion between steel facesheet and GFRP core showed satisfactory mechanical performance. The use of steel facesheet is to protect the GFRP tube core and provide good flexural stiffness.

(2) Increases of the thickness of the steel facesheet could significantly increase the flexural stiffness and ultimate load of the sandwich beams. The flexural rigidity is apparently improved and the mid-span displacement decreases as the facesheet thickness increases. When the facesheet thickness is increased from 4 to $10 \mathrm{~mm}$ in $2 \mathrm{~mm}$ steps, the mid-span displacements are reduced by $8.4 \%, 15.4 \%$, and $11.5 \%$, respectively.

(3) The transformed section method is used for the theoretical calculation of the sandwich panel, and the method of material mechanics is used to deduce the computational formula for the mid-span deflection; the theoretical and experimental values are shown to be in agreement.

(4) The FE modeling approach based on material properties and failure modes obtained from experimental investigations could evaluate the bending performance of steel-GFRP sandwich panels. Results produced by the infinite element simulation and the theoretical value are nearly the same, and the infinite element result is marginally smaller than the experimental value, which is caused by the deficiency of the specimens and other uncertain factors. A $4.5 \mathrm{~mm}$ thick facesheet is appropriate for a sandwich beam with a total height of $95 \mathrm{~mm}$.

\section{Competing Interests}

The authors declare that they have no competing interests.

\section{Acknowledgments}

The research described here was supported by the National Natural Science Foundation of China (Grant nos. 51238003 and 51578285).

\section{References}

[1] S. W. Davey, G. M. V. Erp, and R. Marsh, "Fibre composite bridge decks-an alternative approach," Composites Part A: Applied Science and Manufacturing, vol. 32, no. 9, pp. 1339-1343, 2001.

[2] H. Hu, S. Belouettar, M. Potier-Ferry, and A. Makradi, "A novel finite element for global and local buckling analysis of sandwich beams," Composite Structures, vol. 90, no. 3, pp. 270-278, 2009.
[3] A. F. Daly and J. R. Cuninghame, "Performance of a fibrereinforced polymer bridge deck under dynamic wheel loading," Composites Part A: Applied Science and Manufacturing, vol. 37, no. 8, pp. 1180-1188, 2006.

[4] T. Keller and A.-X. Zhou, "Fatigue behavior of adhesively bonded joints composed of pultruded GFRP adherends for civil infrastructure applications," Composites Part A: Applied Science and Manufacturing, vol. 37, no. 8, pp. 1119-1130, 2006.

[5] M.-F. He and W.-B. Hu, "A study on composite honeycomb sandwich panel structure," Materials and Design, vol. 29, no. 3, pp. 709-713, 2008.

[6] H. G. Allen, Analysis and Design of Structural Sandwich Panel, Pergamon Press, New York, NY, USA, 1969.

[7] J. M. Davies, Lightweight Sandwich Construction, University of Manchester, Manchester, UK, 2001.

[8] Y. Frostig and M. Baruch, "Bending of sandwich beams with transversely flexible core," AIAA Journal, vol. 28, no. 3, pp. 523531, 1990.

[9] D. Frank, J. Romanoff, and H. Remes, "Fatigue strength assessment of laser stake-welded web-core steel sandwich panels," Fatigue \& Fracture of Engineering Materials \& Structures, vol. 36, no. 8, pp. 724-737, 2013.

[10] V. Rubino, V. S. Deshpande, and N. A. Fleck, "The three-point bending of Y-frame and corrugated core sandwich beams," International Journal of Mechanical Sciences, vol. 52, no. 3, pp. 485-494, 2010.

[11] H. Kolsters and D. Zenkert, "Buckling of laser-welded sandwich panels: ultimate strength and experiments," Proceedings of the Institution of Mechanical Engineers, Part M: Journal of Engineering for the Maritime Environment, vol. 224, no. 1, pp. 29-45, 2010.

[12] T. Keller, J. Rothe, J. de Castro, and M. Osei-Antwi, "GFRPbalsa sandwich bridge deck: concept, design, and experimental validation," Journal of Composites for Construction, vol. 18, no. 2, pp. 301-310, 2013.

[13] R. Huo, W. Liu, L. Wan, Y. Fang, and L. Wang, "Experimental study on sandwich bridge decks with GFRP face sheets and a foam-web core loaded under two-way bending," Advances in Materials Science and Engineering, vol. 2015, Article ID 434721, 12 pages, 2015.

[14] D.-W. Seo, K.-T. Park, Y.-J. You, and S.-Y. Lee, "Experimental investigation for tensile performance of GFRP-steel hybridized rebar," Advances in Materials Science and Engineering, vol. 2016, Article ID 9401427, 12 pages, 2016.

[15] Ç. Özes and N. Neşer, "Experimental study on steel to FRP bonded lap joints in marine applications," Advances in Materials Science and Engineering, vol. 2015, Article ID 164208, 6 pages, 2015.

[16] A. G. Mamalis, K. N. Spentzas, N. G. Pantelelis, D. E. Manolakos, and M. B. Ioannidis, "A new hybrid concept for sandwich structures," Composite Structures, vol. 83, no. 4, pp. 335-340, 2008.

[17] ASTM International, "Standard test method for flexural properties of sandwich constructions," ASTM C393-2000, ASTM International, West Conshohocken, Pa, USA, 2000.

[18] W. Prachasaree, A. Sangkaew, S. Limkatanyu, and H. V. S. GangaRao, "Parametric study on dynamic response of fiber reinforced polymer composite bridges," International Journal of Polymer Science, vol. 2015, Article ID 565301, 13 pages, 2015. 
[19] ASTM International, "Standard test method for tensile properties of polymer matrix composite materials," ASTM D3039/ D3039M-14, ASTM International, West Conshohocken, Pa, USA, 2014.

[20] DIAB Sandwich Concept, DIAB Sandwich Handbook, http:// www.diabgroup.com. 

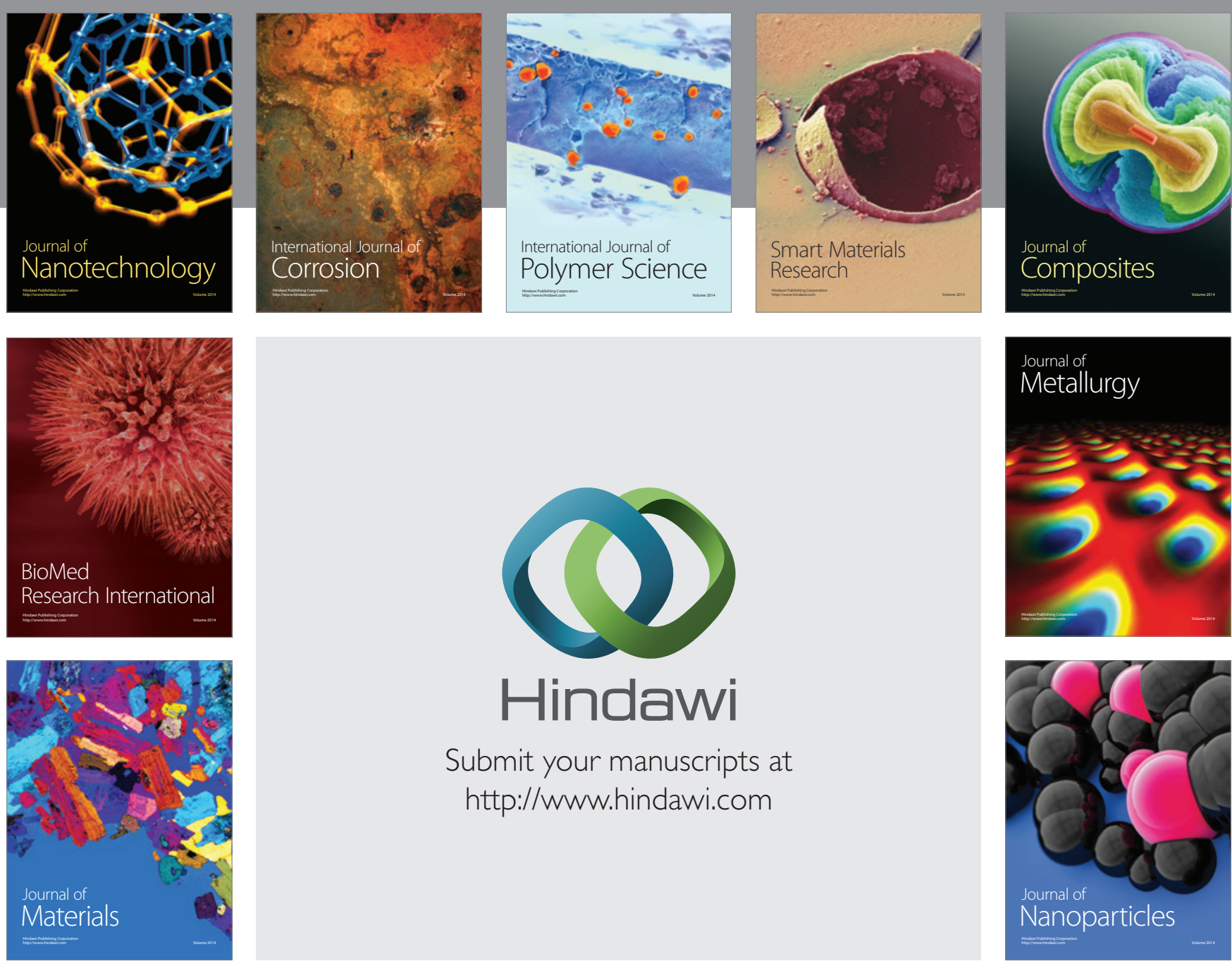

\section{Hindawi}

Submit your manuscripts at

http://www.hindawi.com

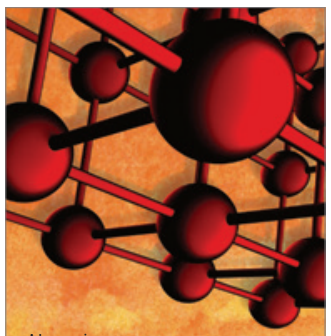

Materials Science and Engineering
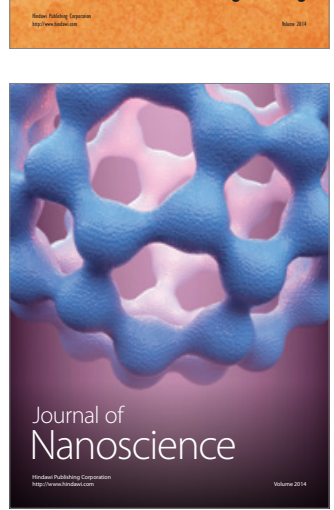
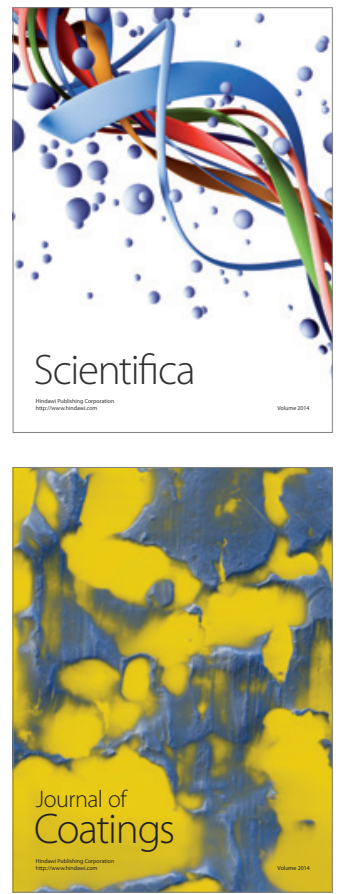
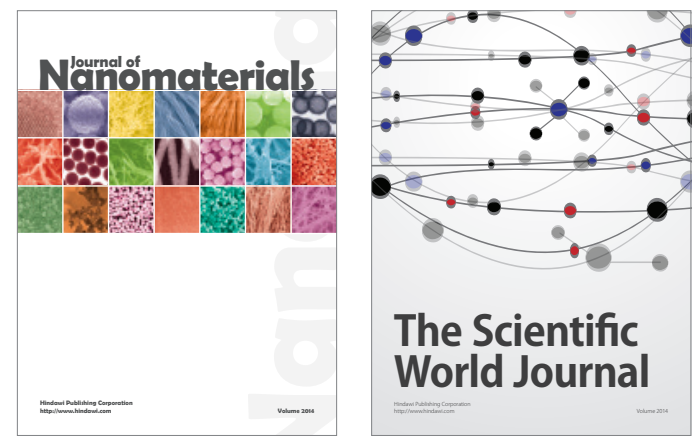

The Scientific World Journal
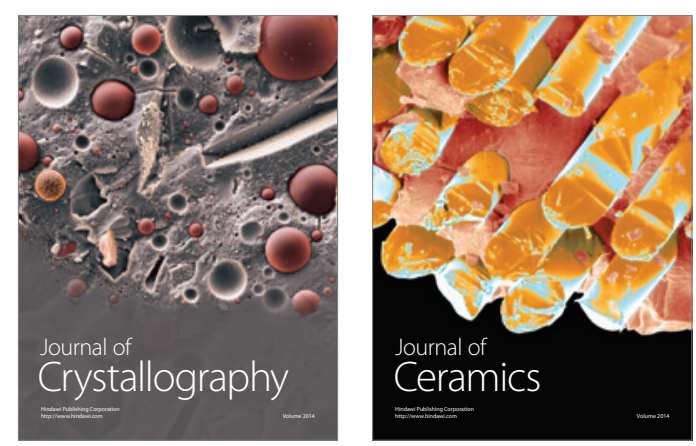
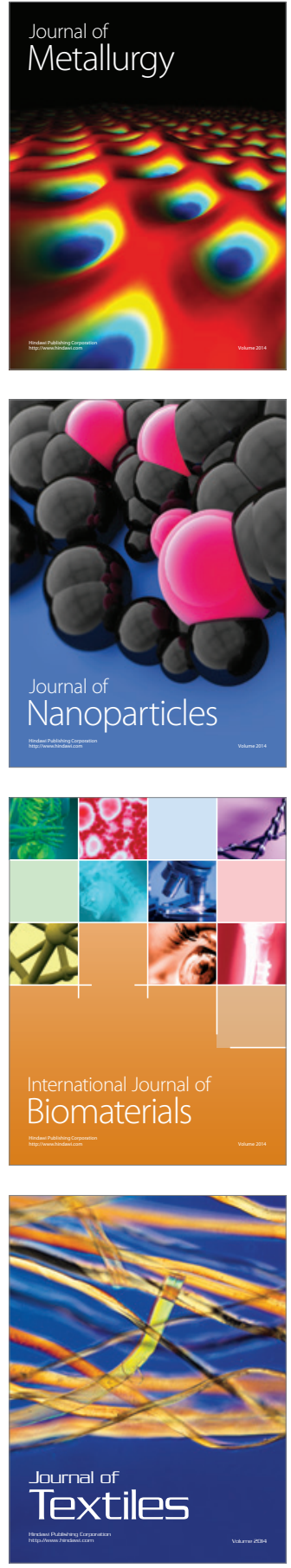